Short-term fluctuations in personal black carbon exposure are associated with rapid changes in carotid arterial stiffening Peer-reviewed author version

PROVOST, Eline; LOUWIES, Tijs; COX, Bianca; op 't Roodt, Jos; SOLMI, Francesca; DONS, Evi; INT PANIS, Luc; DE BOEVER, Patrick \& NAWROT, Tim (2016) Short-term fluctuations in personal black carbon exposure are associated with rapid changes in carotid arterial stiffening. In: ENVIRONMENT INTERNATIONAL, 88, p. 228-234.

DOI: 10.1016/j.envint.2015.12.023

Handle: http://hdl.handle.net/1942/21010 


\section{Short-term fluctuations in personal black carbon exposure are associated with rapid changes in carotid arterial stiffening}

Eline B. Provost ${ }^{1,2}$, Tijs Louwies ${ }^{1,2}$, Bianca Cox ${ }^{1}$, Jos op 't Roodt ${ }^{1,3}$, Francesca Solmi ${ }^{4}$, Evi Dons $^{1,2}$, Luc Int Panis ${ }^{1,5}$, Patrick De Boever ${ }^{1,2}$, Tim S. Nawrot ${ }^{1,6}$

${ }^{1}$ Centre for Environmental Sciences, Hasselt University (UHasselt), Diepenbeek, Belgium; 2Environmental Risk and Health, Flemish Institute for Technological Research (VITO), Mol, Belgium; ${ }^{3}$ Department of Internal Medicine, Maastricht University Medical Centre (MUMC+), Maastricht, The Netherlands; ${ }^{4}$ Interuniversity Institute for Biostatistics and statistical Bioinformatics, Hasselt University (UHasselt), Diepenbeek, Belgium; ${ }^{5}$ School for Mobility, Hasselt University (UHasselt), Diepenbeek, Belgium; ${ }^{6}$ Department of Public Health \& Primary Care, Leuven University (KU Leuven), Leuven, Belgium

Correspondence to: dr. Patrick De Boever, Environmental Risk and Health, VITO NV, Industriezone Vlasmeer 7, $2400 \mathrm{Mol}$, Belgium.

Fax: +32 145805 23, Phone: +32 143351 45, e-mail: patrick.deboever@vito.be

Word count: 6,465 


\section{Abstract}

Background - Vascular changes may underpin the association between airborne black carbon (BC) and cardiovascular events. Accurate assessment of personal exposure is a major challenge in epidemiological research. $\mathrm{BC}$ concentrations are strongly related to time-activity patterns, which is particularly relevant when investigating short-term effects. We investigated associations between arterial stiffness and personal short-term BC exposure.

Methods - This panel study included 54 healthy adults ( $92 \%$ women, mean age 40.7 years). $\mathrm{BC}$ exposure was monitored individually with a micro-aethalometer during one workweek. Functional and structural properties of the carotid artery were examined ultrasonographically on two separate days. The effect of different short-term personal BC exposure windows $(1,2$, $4,6,8,24$ and 48 hours before the ultrasound examination) on carotid artery stiffness was estimated using mixed models while adjusting for other known correlates of arterial stiffness. Results - Median personal BC exposures within the same day ranged from 599.8 to 728.9 $\mathrm{ng} / \mathrm{m}^{3}$ and were associated with carotid arterial stiffness measures. Young's elastic modulus and pulse wave velocity, both measures of stiffness, were positively associated with BC exposure, while the distensibility and compliance coefficient, measures of elasticity, were negatively associated with $\mathrm{BC}$ exposure. The strongest associations were observed with $\mathrm{BC}$ exposure 8 hours before the clinical examination. For each $100 \mathrm{ng} / \mathrm{m}^{3}$ increase in exposure within this time window, Young's elastic modulus increased by $2.38 \%$ (95\% Cl: 0.81 to 3.97; $P=0.0033)$, while the distensibility coefficient decreased by $2.27 \%(95 \% \mathrm{Cl}:-3.62$ to -0.92 ; $P=0.0008)$.

Conclusions - Short-term elevations in personal BC exposure, even within hours, are associated with increased arterial stiffness. This response may reflect a pathway by which air pollution triggers cardiovascular events. 
Key Words: arterial stiffness, carotid artery, air pollution exposure, black carbon, epidemiology 


\section{Introduction}

Increases in particulate air pollution levels have been associated with an increase in cardiovascular morbidity and mortality in numerous epidemiological studies ${ }^{1-3}$. Altered cardiac autonomic function ${ }^{4-6}$, atherosclerosis ${ }^{5-7}$ and changes in vascular function ${ }^{5,6,8}$ are potential pathophysiological pathways through which particulate air pollution can influence the cardiovascular system.

Evidence from animal studies indicates that particulate matter can initiate and accelerate atherosclerosis. ${ }^{9-13}$ Different epidemiological studies show an association between long-term exposure to particulate air pollution and intima-media thickness. Intima-media thickness is a parameter for vascular structural changes that is frequently used as a subclinical marker of atherosclerosis. ${ }^{14}$ Measures of arterial stiffness on the other hand provide a manner to investigate functional vascular changes. Acute changes in vascular stiffness may be a factor in explaining how acute exposure to particulate air pollution can trigger cardiovascular events, such as myocardial infarction. ${ }^{15}$ However, epidemiological studies investigating the association between short-term exposure to particulate air pollution and arterial stiffness are limited. ${ }^{16,17}$ Research by Mehta and colleagues shows that short-term increases in air pollution levels, that were monitored centrally, were associated with changes in the augmentation index and augmentation pressure, both measures of vascular stiffness. ${ }^{17}$ Adamopoulos et al. report cross-sectional associations between augmentation pressure and short-term exposure to particulate matter with a diameter smaller than $10 \mu \mathrm{m}\left(\mathrm{PM}_{10}\right)$ in men. ${ }^{16}$

Black carbon $(\mathrm{BC})$ is formed during traffic-related combustion and $\mathrm{BC}$ concentration is used as a general measure for exposure to traffic particles. ${ }^{18} \mathrm{BC}$ is considered as an important component of particulate air pollution that induces adverse health effects. ${ }^{19,20}$ The estimation 
of individual BC exposure levels is a challenge in epidemiological research. Most studies evaluate individual exposure based on central monitoring stations, estimation models or proxies for exposure such as distance to major roads. These approaches do not consider the fact that individual exposure is strongly related to time-activity patterns. ${ }^{21}$ Modelled exposure based on the place of residence may result in exposure misclassification, especially for traffic-

related $B C$ with high spatio-temporal gradients..$^{21,22}$ Such exposure misclassification may bias results towards the null, leading to an imprecise estimation of the health effects associated with particulate air pollution exposure and $B C$ in particular. ${ }^{22}$ Better personal estimates of $B C$ in relation to location can now be obtained with small continuous BC sensors. ${ }^{21,23,24}$

We report the results of a repeated measures study that analyzed markers related to vascular structure, i.e. carotid intima-media thickness, and to vascular function, i.e. carotid artery stiffness parameters in a cohort of healthy adults. We investigated for the first time the association of the latter parameters with personal short-term exposure to $B C$.

\section{Materials and Methods}

\subsection{Study population}

130 nurses from two hospitals in Belgium, i.e. Ziekenhuis Oost-Limburg (ZOL, Genk) and Universitair Ziekenhuis Antwerpen (UZA, Antwerp), were invited to participate in the study. 99 (76\%) nurses agreed to participate, of which 56 (56\%) were assigned at random to this study. The number of participants was fixed because of the limited availability of the BC measuring devices. We conducted our study according to the principles outlined in the Helsinki declaration for research on human participants. The ethics committee of Hasselt University and Universitair Ziekenhuis Antwerpen approved the study. All participants gave 
written informed consent. A questionnaire provided detailed information on social and medical characteristics of the participants, including transportation modes, use of medication, smoking habits and incidence of cardiovascular disease in their family. All participants reported to be free of clinical cardiovascular diseases and diabetes.

A panel study design was used to investigate the association between measures of arterial stiffness and short-term exposure to BC. BC exposure of the participants was monitored continuously during 7 consecutive days of an average workweek between April and May 2013. Repeated clinical examinations of the same participant were performed on two separate days within this period, i.e. on day 3 and 6 . The examination took place between $7.00 \mathrm{~h}$ and $19.00 \mathrm{~h}$ at the hospital where the nurses worked. During the clinical examination, participants were questioned on their current medication, caffeine and alcohol use, current smoking status and time spent in traffic during the past 24 hours. Smokers $(n=2)$ were excluded from all statistical analyses.

\subsection{Health measurements}

Clinical examinations were performed by one trained observer and included an ultrasound examination of the common carotid artery, blood pressure and heart rate measurements and a single blood test at the end of the week. Measurements on non-fasting blood included blood cell distribution, serum creatinine, $\mathrm{HDL}$ and total cholesterol, blood glucose level and ү-glutamyltransferase (GGT) level, a biomarker for alcohol intake.

\subsubsection{Carotid stiffness measures}

Ultrasound measurements were performed by one trained investigator using an ultrasound device with automatic boundary detection software in RF-mode (MyLabOne, Esaote Benelux, 
Maastricht, The Netherlands) according to previously reported protocols. ${ }^{25}$ Longitudinal scanning of a $1 \mathrm{~cm}$ segment of the right common carotid artery (CCA) at $1 \mathrm{~cm}$ proximal to the dilatation of the carotid bulb visualizes the lumen-intima and media-adventitia interfaces of the far arterial wall. Carotid intima-media thickness (CIMT) was determined under three different angles; i.e. 90, 130 and 180 degrees using Meijer's Arc with the participants at rest for 10 minutes in a supine position, with their head slightly turned to the left, according to the recommendations of the Mannheim Carotid Intima-Media Thickness Consensus. ${ }^{26}$ Measurements obtained at the three angles were averaged.

The carotid distensibility (DC) and compliance (CC) coefficients are inversely related to arterial stiffness such that higher values of these parameters represent less stiffness; whereas pulse wave velocity (PWV) is a direct measure of arterial stiffness. These parameters are derived from the ultrasound measurements averaged over 8 cardiac cycles and from supine brachial blood pressure measured during the ultrasound examination. We computed the distensibility and compliance coefficients from the diastolic cross-sectional area (A), the systolic increase in cross-sectional area $(\Delta A)$ and the local pulse pressure $(\Delta P)$ according to the formula: $D C=(\Delta A / A) / \Delta P$ and $C C=\Delta A / \Delta P .{ }^{27} A$ and $\Delta A$ were calculated as $A=\pi \times(D / 2)^{2}$ and $\Delta A=\pi \times[(D+\Delta D) / 2]^{2}-\pi \times(D / 2)^{2}$. Pulse wave velocity was calculated as $P W V=1 / \sqrt{\rho \times D C}$ with $\rho$ as blood density. Young's Elastic Modulus (YEM) combines measures of arterial wall elasticity with wall thickness and increases in YEM represent an increase in arterial stiffness. Young's Elastic Modulus is calculated as YEM= D/(CIMT x DC).

Intra-observer coefficients of variation ranged from $5.61 \%$ to $11.91 \%$ for the different stiffness parameters, indicating good reproducibility of the measurements. These results are in line with previously published results on variability and reproducibility of carotid structural 
and functional parameters assessed with transcutaneous ultrasound by Caviezel and colleagues in the SAPALDIA cohort. ${ }^{28}$

\subsubsection{Blood pressure and heart rate}

Blood pressure and heart rate were measured according to the guidelines of the European Society of Hypertension. ${ }^{29}$ Participants rested for five minutes, after which heart rate (HR), systolic (SBP) and diastolic (DBP) blood pressure were measured five times consecutively with an automated device (Omron 705 IT, MSH, Glabbeek, Belgium). The average of the last three measurements was used to calculate mean arterial pressure.

\subsection{Personal BC exposure assessment}

Measurements of $\mathrm{BC}$ were recorded in one minute intervals using the portable MicroAeth ${ }^{\circledR}$ Model AE51 BC aerosol monitor (AethLabs, San Francisco, CA, USA). A short tube was attached to the inlet of the device, which allowed participants to put the portable device in their pocket, purse or backpack. The filter was replaced every two days to prevent filter saturation. The participants were instructed to take the instrument wherever they went. When the participants were indoors, they were allowed to keep the instrument static in the room where the majority of their time was spent.

Air was drawn in over a Teflon-coated borosilicate glass fiber filter at a flow rate of $100 \mathrm{ml} / \mathrm{min}$. The attenuation of light was measured at a wavelength of $880 \mathrm{~nm}$ to determine $\mathrm{BC}$ accumulation on the filter. The attenuation information was used to calculate the $\mathrm{BC}$ concentration using an assigned calibration factor. Measurements with high attenuation $(>75)$ or an error code were excluded from the analyses. Data were smoothened with EPAalgorithms before further processing. ${ }^{30}$ Exposure to $B C$ was measured for each participant 
during seven consecutive days. $\mathrm{BC}$ exposure, expressed as $\mathrm{ng} / \mathrm{m}^{3}$, was calculated $1,2,4,6,8$, 24 and 48 hours before the clinical examination.

\subsection{Statistical analysis}

SAS software (version 9.4, SAS Institute Inc., Cary, NC, USA) was used for database management and statistical analysis. The effect of $\mathrm{BC}$ exposure on the different arterial stiffness measures was investigated using the MIXED procedure to account for the clustered data within the same person, i.e. two measurements that were taken three days apart from each other. A random intercept model was used and the coefficients and standard errors were estimated under restricted maximum likelihood estimation (REML) with unstructured autocorrelation. The hospital where the measurements were performed was included as a random effect.

We adjusted for an a priori chosen list of covariates including gender, age, body mass index (BMI), mean arterial pressure, total/HDL cholesterol ratio, glucose level, alcohol consumption, smoking status, apparent temperature, day of the week and hour of the clinical examination. Both linear and quadratic terms of age were tested. The quadratic term was not significant and was therefore removed from the models. Q-Q plots of the residuals were used to test the assumptions of all models. These assumptions were met after log10transformation of the arterial stiffness measures, i.e. YEM, PWV, DC and CC. Descriptive statistics are therefore given as geometric mean with $25^{\text {th }}-75^{\text {th }}$ percentile interval for these variables. Estimates associated with a $100 \mathrm{ng} / \mathrm{m}^{3}$ increase in $\mathrm{BC}$ exposure at the given hour lag before the clinical examination for each of the arterial stiffness measures are given as a percent change $\left[100 \times\left(10^{\beta}-1\right)\right]$. 
Men $(n=4)$ were excluded as a sensitivity analysis. Separate mixed models that included terms for within- and between-subject BC exposure were fitted in addition to the main model because we considered the possibility of differences in between- and within-subject air pollution effects. Fitting these models excludes confounding by subject-specific characteristics that do not vary over time. ${ }^{31}$

In a final analysis, we entered the different lags for BC (lags 1, 2, 4, 6, 8, 24, and 48) in one model by using distributed lag non-linear models (DLNM), which has the advantage of providing cumulative effects of $\mathrm{BC}$ exposure by flexibly estimating contributions at different lag times. ${ }^{32}$ The DLNM is defined through a "cross-basis" function, which allows the simultaneous estimation of a non-linear exposure-response association and non-linear effects across lags. We assumed a linear exposure-response association and we used different specifications to model the lag structure: a linear function, a natural cubic spline with $3 \mathrm{df}$ (with knots at equally spaced values in the original lag scale), and an unconstrained distributed lag model (in which each lag is entered as a separate variable). Because of the correlation between lags, the unconstrained distributed lag model will result in unstable estimates for the individual lags, but it is known as more flexible and less prone to bias for the estimate of the overall effect. ${ }^{33}$ These analyses were performed with the statistical software R (R Foundation for Statistical Computing, Vienna, Austria) using the "dlnm" package. ${ }^{34}$

\section{Results}

\subsection{Study population and exposure characteristics}

Table 1. Description of the study population. 


\section{Personal characteristics}

Age, years

$40.7 \pm 10.7$

Female

$50(92.9 \%)$

Smoking status

Former

$14(25.9 \%)$

Never

$40(74.1 \%)$

Statin users

$3(5.6)$

\section{General health characteristics}

Body Mass Index (BMI), kg/m²

$23.9 \pm 4.2$

Mean Arterial Pressure, $\mathrm{mm} \mathrm{Hg}$

$83.0 \pm 7.6$

Heart Rate, beats per minute

$77.8 \pm 23.4$

Total/HDL cholesterol ratio

$2.6 \pm 0.8$

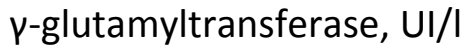

$17.4 \pm 12.3$

Glucose, mg/dl

$91.0 \pm 15.8$

\section{Common carotid artery parameters}

Intima-Media Thickness (CIMT), $\mu \mathrm{m}$

$580.6 \pm 116.5$

Young's Elastic Modulus (YEM), kPa

$552.5(386.8-737.8)$

Pulse Wave Velocity (PWV), $\mathrm{m} / \mathrm{s}$

$6.71(5.68-7.78)$

Distensibility coefficient (DC), $10^{-3} / \mathrm{kPa}$

$21.1(15.6-29.3)$

Compliance coefficient (CC), $\mathrm{mm}^{2} / \mathrm{kPa}$

$0.73(0.57-1.04)$

Values are number (\%) or arithmetic mean \pm SD, except for the arterial stiffness parameters (YEM, PWV, DC, CC) for which geometric mean $\left(25^{\text {th }}-75^{\text {th }}\right.$ percentile $)$ is given.

The study population included 54 nurses ( $92.9 \%$ female) aged 22 to 56 years (Table 1). $74.1 \%$ had never smoked. BMI averaged (SD) $23.9(4.2) \mathrm{kg} / \mathrm{m}^{2}$ and the participants had an average systolic and diastolic blood pressure of 115.2 (10.4) and 72.1 (8.0) $\mathrm{mm} \mathrm{Hg}$, respectively. Three (5.6\%) participants used statins and one participant was on anti-hypertensive medication. The total/HDL cholesterol ratio averaged $2.6(0.8)$. The average $\gamma$-glutamyltransferase level was $17.4(12.3) \mathrm{UI} / \mathrm{I}$ and the glucose level 91.0 (15.8) mg/dl. Mean CIMT of the participants was 
580.6 (116.5) $\mu \mathrm{m}$. The different carotid artery stiffness measures, i.e. YEM, PWV, DC and CC, averaged $\left(25^{\text {th }}-75^{\text {th }}\right.$ percentile) $552.5(3386.8-737.8) \mathrm{kPa}, 6.71(5.68-7.78) \mathrm{m} / \mathrm{s}, 21.1$ (15.629.3) $10^{-3} / \mathrm{kPa}$ and $0.73(0.57-1.04) \mathrm{mm}^{2} / \mathrm{kPa}$, respectively. Median personal $\mathrm{BC}$ exposure ranged from 599.8 to $728.9 \mathrm{ng} / \mathrm{m}^{3}$ over the different hour lags before the clinical examination (Table 2). Apparent temperature on the day of the clinical examination ranged from 6.4 to $15.1^{\circ} \mathrm{C}$.

Table 2. Exposure characteristics.

$\begin{array}{cc}\begin{array}{c}\text { Personal black carbon }(\mathrm{BC}), \mathbf{n g} / \mathbf{m}^{\mathbf{3}} \\ \text { 1h-lag }\end{array} & \\ \text { 2h-lag } & 642.7(251.4-1469.8) \\ \text { 4h-lag } & 641.3(275.5-1455.8) \\ \text { 6h-lag } & 619.8(259.0-1401.9) \\ \text { 8h-lag } & 599.8(300.3-1310.6) \\ \text { 24h-lag } & 686.9(392.7-1237.0) \\ \text { 48h-lag } & 711.3(528.8-1033.6) \\ & 728.9(503.3-983.2)\end{array}$

\section{Apparent temperature, ${ }^{\circ} \mathrm{C}$ \\ $8.9(8.4-11.8)$}

Values are median $\left(25^{\text {th }}-75^{\text {th }}\right.$ percentile $)$ at different hour lags, except for temperature which is given for the day of the clinical examination.

\subsection{Short-term BC exposure and arterial stiffening}

The different short-term BC exposure windows before the clinical examination were significantly associated with all measures of carotid arterial stiffness, as shown in Figure 1. Specifically, increases in $\mathrm{BC}$ exposure 1 to 8 hours before the ultrasound examination were significantly associated with increased arterial stiffness. Increases in YEM (Figure 1A) ranged from $1.20 \%(95 \% \mathrm{Cl}: 0.48$ to $1.95 ; P=0.0016)$ to $2.38 \%(95 \% \mathrm{Cl}: 0.81$ to $3.97 ; P=0.0033$ ) for 
each $100 \mathrm{ng} / \mathrm{m}^{3}$ increase in BC exposure 1 to 8 hours before the clinical examination. Similar increases in PWV (Figure 1B) are shown for the same hour lags, ranging from $0.51 \%(95 \% \mathrm{Cl}$ : 0.19 to $0.83, P=0.0025)$ to $1.18 \%$ (95\% Cl: 0.51 to $1.88 ; P=0.0008)$.

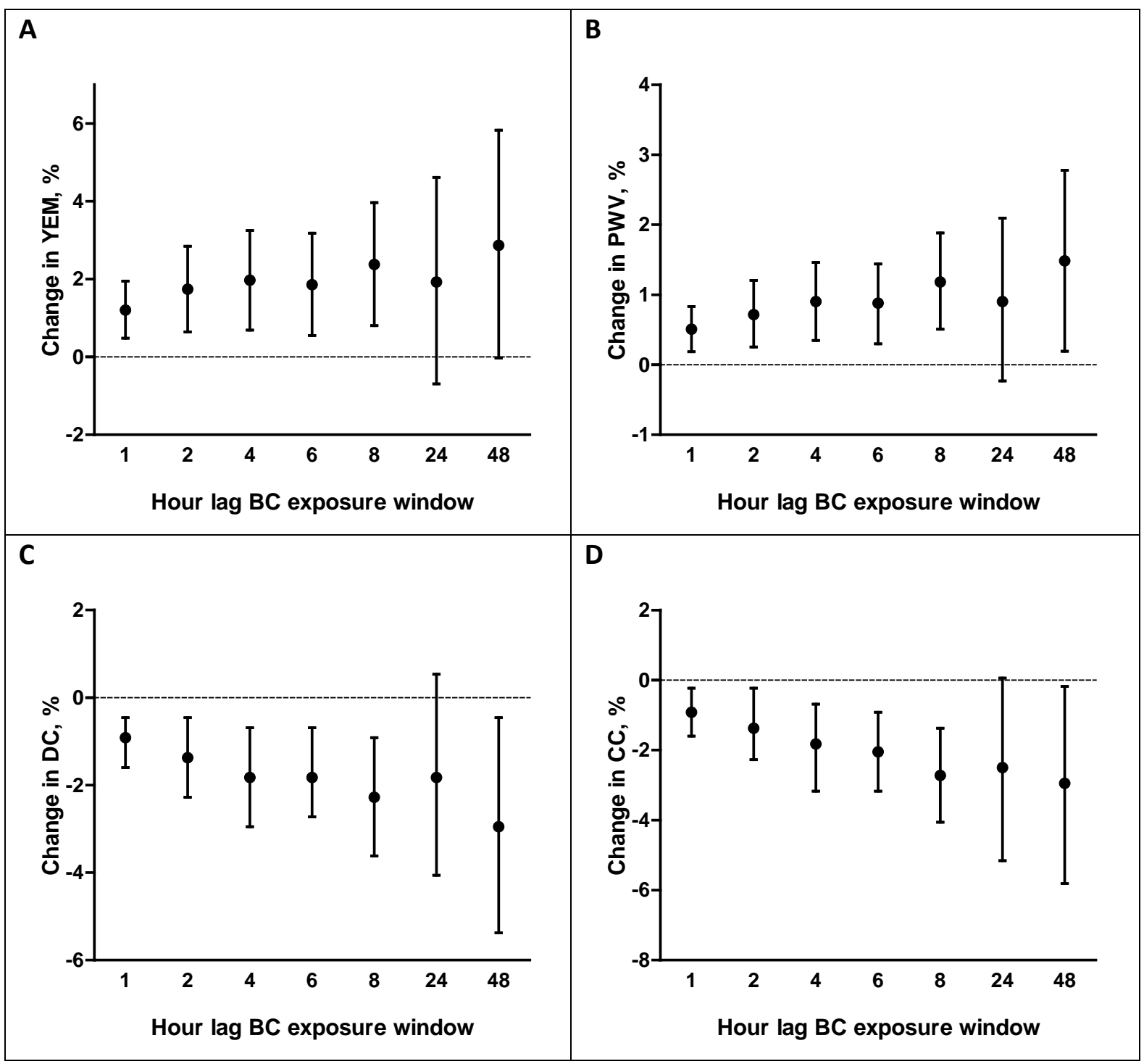

Figure 1. Percent change in carotid (A) Young's Elastic Modulus (YEM), (B) Pulse Wave Velocity (PWV),

(C) Distensibility Coefficient (DC) and (D) Compliance Coefficient (CC) associated with a $100 \mathrm{ng} / \mathrm{m}^{3}$ higher personal exposure to black carbon $(\mathrm{BC})$ at different hour lags prior to the clinical examination. The analyses were adjusted for gender, age, body mass index, mean arterial pressure, total/HDL cholesterol ratio, glucose level, alcohol consumption, smoking status, apparent temperature, day of the week and hour of the clinical examination. 
The indirect measures of carotid arterial stiffness, i.e. DC and CC, were significantly associated with $\mathrm{BC}$ exposure at the various hourly lags. DC (Figure $1 \mathrm{C}$ ) decreased by $-0.92 \%$ (95\% Cl: -1.60 to $-0.46 ; P=0.0025)$ to $-2.27 \%(95 \% \mathrm{Cl}:-3.62$ to $-0.92 ; P=0.0008)$ in association with a $100 \mathrm{ng} / \mathrm{m}^{3}$ increase in BC exposure 1 to 8 hours before the clinical examination. Similar decreases were found for CC (Figure 1D) within these time windows, ranging from $-0.92 \%$ (95\% Cl: -1.60 to $-0.23 ; P=0.0077)$ to $-2.73 \%(95 \% \mathrm{Cl}:-4.06$ to $-1.37 ; P=0.0003)$.

BC exposure at lag 24-hour was not significantly associated with any measure of carotid arterial stiffness, while the lag 48-hour reached statistical significance in association with PWV, DC and CC.

Our study population included four men. Excluding them from the analyses did not alter the previous reported associations. Separate mixed models to differentiate between the within- and between-subject effects were evaluated. Results showed that the reported associations are driven by within-subject effects, which were statistically significant and similar in effect size compared to the results from the main analysis, while the betweensubject effects were not statistically significant.

Finally, we estimated the cumulative effects of $\mathrm{BC}$ exposure over the different time lags using a DLNM model. Results showed a cumulative effect of BC exposure on the different arterial stiffness measures. The estimated change in PWV associated with a $100 \mathrm{ng} / \mathrm{m}^{3}$ increase in cumulative $\mathrm{BC}$ exposure ranged from $1.50 \%$ (95\% $\mathrm{Cl}: 0.35$ to 2.66$)$ to $1.85 \%$ (95\% $\mathrm{Cl}: 0.43$ to 3.29 ) depending on the used lag structure (linear, natural cubic spline or unconstrained). Similarly, the estimated change in YEM ranged from 1.66\% (95\% Cl: -1.79 to 5.23 ) to $2.44 \%$ ( $95 \% \mathrm{Cl}:-0.82$ to 5.81 ) for each $100 \mathrm{ng} / \mathrm{m}^{3}$ increase in cumulative $\mathrm{BC}$ exposure. Estimated changes in DC and CC ranged from $-3.60 \%(95 \% \mathrm{Cl}:-6.28$ to -0.85$)$ to $-2.93 \%$ (95\% 
$\mathrm{Cl}:-5.12$ to -0.69$)$ and from $-3.63 \%(95 \% \mathrm{Cl}:-5.97$ to -1.23$)$ to $-3.06 \%(95 \% \mathrm{Cl}:-6.18$ to 0.17$)$, respectively.

\section{Discussion}

This study documents rapid changes, within hours, in vascular stiffening of the carotid artery in association with personal $B C$ exposure during the hours before the clinical examination. Young's elastic modulus and pulse wave velocity, both direct measures of stiffness, were positively associated with BC exposure, while the distensibility and compliance coefficient, both measures of elasticity, were negatively associated with $\mathrm{BC}$ exposure during all hour lags before the clinical examination (Figure 1). These associations were independent of other cardiovascular risk factors, including gender, age, BMI, mean arterial pressure and total/HDL cholesterol ratio. Our results were consistent for the different measures of arterial stiffness both within and cumulated over the different exposure windows.

To date, three intervention studies ${ }^{35-37}$, two studies focusing on long-term exposure ${ }^{38,}$ 39 and two studies using short-term exposures ${ }^{16,17}$ investigated the consequences of air pollution on arterial stiffness. However, none of these studies looked specifically at the impact of personal $B C$ exposure or discriminated between different hour lags on the day of the arterial stiffness assessment. Adamopoulos and colleagues identified a positive association between $\mathrm{PM}_{10}$ exposure averaged over 5 days and augmentation pressure, though only in men. ${ }^{16}$ Within the Veterans Affairs Normative Aging Study, results show an association between centrally monitored $\mathrm{PM}_{2.5}$ at a 3-day moving average lag and the augmentation index, an indirect measure of arterial stiffening. ${ }^{17}$ The fact that no association with same day $\mathrm{BC}$ or other exposure lags was found in the latter study might be driven by the discrepancies 
in personal $\mathrm{BC}$ exposures and centrally monitored $\mathrm{BC}$ data, with the latter leading to a possible reduction of the effect estimates because of exposure misclassification. Comparably, Suh and Zanobetti reported a significant association between heart rate variability and personally monitored elemental carbon. ${ }^{40}$ However, when they used centrally monitored ambient elemental carbon, the association was considerably smaller and no longer statistically significant, further highlighting potential underestimation of the health effects when using modelled air pollution data due to exposure misclassification. ${ }^{22,41}$

Although changes in arterial stiffness are unlikely to be of significance in healthy individuals, they may be of clinical importance in susceptible individuals. Arterial stiffness is a strong predictor of future cardiovascular events and all-cause mortality, especially in subjects with higher baseline cardiovascular risk. ${ }^{15} \mathrm{An}$ acute response in arterial stiffness may reflect an underlying mechanism by which particulate matter triggers an increased risk of cardiovascular events. Recent meta-analyses have shown that exposure to particulate air pollution is associated with a near-term increase in risk of myocardial infarction ${ }^{42}$, heart failure $\mathrm{A}^{43}$ and stroke $\mathrm{s}^{44}$. These associations were the strongest with same day exposure. Our results show a rapid increase in arterial stiffness associated with short-term increases in BC concentrations at different exposure windows ranging from 1 to 48 hours before the clinical examination. However, strong correlations between the BC concentrations at these different time windows make it more difficult to identify the most vulnerable exposure window. We observed that the cumulative effect of BC exposure over the different lags is similar in effect size compared to the lag-specific effects, showing that these lag-specific effects are not additive.

Similar to our study, Brook and colleagues report an association between brief increases in personal $\mathrm{PM}_{2.5}$ exposure at lags 1 to 10 hours and small increases in heart rate as 
well as a non-significant trend toward endothelial dysfunction as measured by flow-mediated dilatation. ${ }^{45}$ Comparably, Krishnan et al. found no significant association between short-term variation in central-site monitored $\mathrm{PM}_{2.5}$ and flow-mediated dilatation in the Multi-Ethnic Study of Air Pollution study. ${ }^{46}$ These results suggest that changes in arterial stiffness may only be partially mediated through changes in endothelial function. There is a complex interaction between the autonomic nervous system and vascular function. Autonomic nervous system imbalance is therefore another plausible pathway via which particulate air pollution can affect arterial stiffness. This is supported by evidence from He et al. showing a time course of the $\mathrm{PM}_{2.5}$ effect on autonomic modulation with the strongest effects occurring between 4-6 hours. $^{47}$

Oxidative stress ${ }^{48}$ and inflammation ${ }^{49}$ are main drivers of stiffening of the vascular wall. In this regard, it is known that exposure to $B C$ causes both local lung as well as systemic inflammation. ${ }^{50,51}$ Free radicals may reduce nitric oxide and increase vasoconstrictor agents such as angiotensin, endothelin, prostaglandins to aggravate arterial stiffness. ${ }^{52,53}$ These potential pathways have been corroborated in a controlled exposure study by Peretz and colleagues $^{54}$ who showed an increase in plasma endothelin-1 levels alongside vasoconstriction in adults exposed to diesel exhaust.

The results from our panel study are in line with the outcomes from experimental studies. Lundbäck and colleagues report an acute increase in arterial stiffness associated with controlled exposure to diesel exhaust ${ }^{36}$, with similar effect sizes reported for exposure to tobacco smoke $\mathrm{e}^{55}$, including second-hand smoke ${ }^{56}$, wood smoke from biomass combustion ${ }^{35}$ or welders exposed to metal-rich particulate matter ${ }^{37}$. Reversely, Lucking and colleagues have demonstrated that removing the particles from exhaust prevents several adverse vascular effects. ${ }^{57}$ 
Our study has a small number of participants $(n=54)$ due to the limited availability of personal monitoring devices. However, application of these personal exposure measurements enabled us to obtain accurate exposure measures leading to significant and robust associations. Although we cannot distinguish between different sources of personal BC exposure, which apart from traffic can also include indoor sources such as cooking, examining the participants at the same time of day during the two clinical examinations reduces source-specific variability in exposure within the same subject.

We have studied a panel of mostly women who reported to be free from clinically diagnosed cardiovascular diseases. A homogeneous study population reduces betweenindividual variability and increases the statistical power in a small panel. The use of an ultrasound device with automatic boundary detection software allowed for a precise visualization and calculation of the common carotid artery measures, independent of investigator interpretation. Intra-observer coefficients of variation were low for the different arterial elasticity measurements, indicating good reproducibility. In addition, the repeated measures allowed us to accurately assess intima-media thickness. Intima-media thickness does not change over a period of one week and the within-subject coefficient of variation should therefore be small. The within-subject coefficient of variation $( \pm S E$ ) was $0.53 \pm 3.05 \%$, indicating good agreement between the two repeated measurements. This documents the robustness of the technique, the observer's qualifications and suggests that the observed dynamic differences in arterial stiffness are unlikely attributable to measurement error.

Although we cannot exclude some level of residual confounding, it is unlikely that unmeasured confounders would eliminate the observed arterial stiffening - black carbon association due to our repeated design. By fitting models that included within- and betweensubject $B C$ exposure, we excluded the risk of confounding due to subject-specific 
characteristics. Results from these analyses showed that the reported associations are driven by within-subject effects, further validating our findings.

\section{Conclusions}

Short-term elevations in airborne black carbon concentration, as measured with personal monitoring devices, are associated with increased stiffness of the carotid artery as reflected by increased pulse wave velocity and Young's elastic modulus as well as a lower distensibility and compliance. This response may reflect a pathway by which air pollution triggers cardiovascular events.

\section{Acknowledgments}

The authors thank the nurses at ZOL and UZA for their enthusiastic participation in this study.

\section{Funding Sources}

This work was supported by the EU Program "Ideas" [ERC-2012-StG 310898] and Research Foundation - Flanders (FWO) [G087311]; E.B.P. has a VITO-FWO PhD fellowship, T.L. has a VITO PhD fellowship and E.D. holds a VITO-FWO Postdoc scholarship.

\section{Disclosures}

None. 


\section{References}

1. Nawrot TS, Perez L, Kunzli N, Munters E, Nemery B. Public health importance of triggers of myocardial infarction: a comparative risk assessment. Lancet. 2011; 377: 732-740.

2. Brook RD, Rajagopalan S, Pope CA, 3rd, Brook JR, Bhatnagar A, Diez-Roux AV, Holguin F, Hong Y, Luepker RV, Mittleman MA, Peters A, Siscovick D, Smith SC, Jr., Whitsel L, Kaufman JD. Particulate matter air pollution and cardiovascular disease: An update to the scientific statement from the American Heart Association. Circulation. 2010; 121 : 2331-2378.

3. Pope CA, 3rd, Dockery DW. Health effects of fine particulate air pollution: lines that connect. J Air Waste Manag Assoc. 2006; 56: 709-742.

4. Pieters $N$, Plusquin $M$, Cox $B$, Kicinski $M$, Vangronsveld J, Nawrot TS. An epidemiological appraisal of the association between heart rate variability and particulate air pollution: a meta-analysis. Heart. 2012; 98: 1127-1135.

5. Sun Q, Hong X, Wold LE. Cardiovascular effects of ambient particulate air pollution exposure. Circulation. 2010; 121: 2755-2765.

6. Mills NL, Donaldson K, Hadoke PW, Boon NA, MacNee W, Cassee FR, Sandstrom T, Blomberg A, Newby DE. Adverse cardiovascular effects of air pollution. Nat Clin Pract Cardiovasc Med. 2009; 6: 36-44.

7. Provost EB, Madhloum N, Int Panis L, De Boever P, Nawrot TS. Carotid intima-media thickness, a marker of subclinical atherosclerosis, and particulate air pollution exposure: the meta-analytical evidence. PLoS One. 2015; 10: e0127014. 
8. Brook RD, Brook JR, Urch B, Vincent R, Rajagopalan S, Silverman F. Inhalation of fine particulate air pollution and ozone causes acute arterial vasoconstriction in healthy adults. Circulation. 2002; 105: 1534-1536.

9. Chen LC, Quan C, Hwang JS, Jin X, Li Q, Zhong M, Rajagopalan S, Sun Q. Atherosclerosis lesion progression during inhalation exposure to environmental tobacco smoke: a comparison to concentrated ambient air fine particles exposure. Inhal Toxicol. 2010; 22: 449-459.

10. Araujo JA, Nel AE. Particulate matter and atherosclerosis: role of particle size, composition and oxidative stress. Part Fibre Toxicol. 2009; 6: 24.

11. Niwa $\mathrm{Y}$, Hiura $\mathrm{Y}, \mathrm{Murayama} \mathrm{T}$, Yokode $\mathrm{M}$, Iwai N. Nano-sized carbon black exposure exacerbates atherosclerosis in LDL-receptor knockout mice. Circ J. 2007; 71: 11571161.

12. Sun Q, Wang A, Jin X, Natanzon A, Duquaine D, Brook RD, Aguinaldo JG, Fayad ZA, Fuster V, Lippmann M, Chen LC, Rajagopalan S. Long-term air pollution exposure and acceleration of atherosclerosis and vascular inflammation in an animal model. JAMA. 2005; 294: 3003-3010.

13. Suwa T, Hogg JC, Quinlan KB, Ohgami A, Vincent R, van Eeden SF. Particulate air pollution induces progression of atherosclerosis. J Am Coll Cardiol. 2002; 39: 935-942.

14. Bauer M, Caviezel S, Teynor A, Erbel R, Mahabadi AA, Schmidt-Trucksass A. Carotid intima-media thickness as a biomarker of subclinical atherosclerosis. Swiss Med Wkly. 2012; 142: w13705.

15. Vlachopoulos C, Aznaouridis K, Stefanadis C. Prediction of cardiovascular events and all-cause mortality with arterial stiffness: a systematic review and meta-analysis. J Am Coll Cardiol. 2010; 55: 1318-1327. 
16. Adamopoulos D, Vyssoulis G, Karpanou E, Kyvelou SM, Argacha JF, Cokkinos D, Stefanadis C, van de Borne P. Environmental determinants of blood pressure, arterial stiffness, and central hemodynamics. J Hypertens. 2010; 28: 903-909.

17. Mehta AJ, Zanobetti A, Koutrakis P, Mittleman MA, Sparrow D, Vokonas P, Schwartz J. Associations between short-term changes in air pollution and correlates of arterial stiffness: The Veterans Affairs Normative Aging Study, 2007-2011. Am J Epidemiol. 2014; 179: 192-199.

18. Richmond-Bryant J, Saganich C, Bukiewicz L, Kalin R. Associations of PM2.5 and black carbon concentrations with traffic, idling, background pollution, and meteorology during school dismissals. Sci Total Environ. 2009; 407: 3357-3364.

19. Janssen NA, Hoek $G$, Simic-Lawson $M$, Fischer $P$, van Bree $L$, ten Brink $H$, Keuken $M$, Atkinson RW, Anderson HR, Brunekreef B, Cassee FR. Black carbon as an additional indicator of the adverse health effects of airborne particles compared with PM10 and PM2.5. Environ Health Perspect. 2011; 119: 1691-1699.

20. Grahame TJ, Klemm R, Schlesinger RB. Public health and components of particulate matter: the changing assessment of black carbon. J Air Waste Manag Assoc. 2014; 64: $620-660$.

21. Dons E, Panis LI, Van Poppel M, Theunis J, Willems H, Torfs R, Wets G. Impact of timeactivity patterns on personal exposure to black carbon. Atmos Environ. 2011; 45: 35943602.

22. Alexeeff SE, Schwartz J, Kloog I, Chudnovsky A, Koutrakis P, Coull BA. Consequences of kriging and land use regression for PM2.5 predictions in epidemiologic analyses: insights into spatial variability using high-resolution satellite data. J Expo Sci Environ Epidemiol. 2015; 25: 138-144. 
23. Nieuwenhuijsen MJ, Donaire-Gonzalez D, Rivas I, de Castro M, Cirach M, Hoek G, Seto $E$, Jerrett $M$, Sunyer J. Variability in and agreement between modeled and personal continuously measured black carbon levels using novel smartphone and sensor technologies. Environ Sci Technol. 2015; 49: 2977-2982.

24. Setton E, Marshall JD, Brauer M, Lundquist KR, Hystad P, Keller P, Cloutier-Fisher D. The impact of daily mobility on exposure to traffic-related air pollution and health effect estimates. J Expo Sci Environ Epidemiol. 2011; 21: 42-48.

25. Stein JH, Korcarz CE, Hurst RT, Lonn E, Kendall CB, Mohler ER, Najjar SS, Rembold CM, Post WS, American Society of Echocardiography Carotid Intima-Media Thickness Task F. Use of carotid ultrasound to identify subclinical vascular disease and evaluate cardiovascular disease risk: a consensus statement from the American Society of Echocardiography Carotid Intima-Media Thickness Task Force. Endorsed by the Society for Vascular Medicine. J Am Soc Echocardiogr. 2008; 21: 93-111.

26. Touboul PJ, Hennerici MG, Meairs S, Adams H, Amarenco P, Bornstein N, Csiba L, Desvarieux M, Ebrahim S, Fatar M, Hernandez Hernandez R, Jaff M, Kownator S, Prati P, Rundek T, Sitzer M, Schminke U, Tardif JC, Taylor A, Vicaut E, Woo KS, Zannad F, Zureik M. Mannheim carotid intima-media thickness consensus (2004-2006). An update on behalf of the Advisory Board of the 3rd and 4th Watching the Risk Symposium, 13th and 15th European Stroke Conferences, Mannheim, Germany, 2004, and Brussels, Belgium, 2006. Cerebrovasc Dis. 2007; 23: 75-80.

27. O'Rourke MF, Staessen JA, Vlachopoulos C, Duprez D, Plante GE. Clinical applications of arterial stiffness; definitions and reference values. Am J Hypertens. 2002; 15: 426444. 
28. Caviezel S, Dratva J, Schaffner E, Teynor A, Baumstark MW, Schindler C, de Groot E, Burdet L, Rothe T, Pons M, Gaspoz JM, Rochat T, Kunzli N, Probst-Hensch N, SchmidtTrucksass A. Variability and reproducibility of carotid structural and functional parameters assessed with transcutaneous ultrasound - results from the SAPALDIA Cohort Study. Atherosclerosis. 2013; 231: 448-455.

29. Parati G, Stergiou GS, Asmar R, Bilo G, de Leeuw P, Imai Y, Kario K, Lurbe E, Manolis A, Mengden T, O'Brien E, Ohkubo T, Padfield P, Palatini P, Pickering T, Redon J, Revera M, Ruilope LM, Shennan A, Staessen JA, Tisler A, Waeber B, Zanchetti A, Mancia G, Monitoring ESHWGoBP. European Society of Hypertension guidelines for blood pressure monitoring at home: a summary report of the Second International Consensus Conference on Home Blood Pressure Monitoring. J Hypertens. 2008; 26: $1505-1526$.

30. Dons E, Int Panis L, Van Poppel M, Theunis J, Wets G. Personal exposure to Black Carbon in transport microenvironments. Atmos Environ. 2012; 55: 392-398.

31. Neuhaus JM, Kalbfleisch JD. Between- and within-cluster covariate effects in the analysis of clustered data. Biometrics. 1998; 54: 638-645.

32. Gasparrini A, Armstrong B, Kenward MG. Distributed lag non-linear models. Stat Med. 2010; 29: 2224-2234.

33. Schwartz J. The distributed lag between air pollution and daily deaths. Epidemiology. 2000; 11: 320-326.

34. Gasparrini A. Distributed Lag Linear and Non-Linear Models in R: The Package dlnm. J Stat Softw. 2011; 43: 1-20.

35. Unosson J, Blomberg A, Sandstrom T, Muala A, Boman C, Nystrom R, Westerholm R, Mills NL, Newby DE, Langrish JP, Bosson JA. Exposure to wood smoke increases arterial 
stiffness and decreases heart rate variability in humans. Part Fibre Toxicol. 2013; 10 :

20.

36. Lundback M, Mills NL, Lucking A, Barath S, Donaldson K, Newby DE, Sandstrom T, Blomberg A. Experimental exposure to diesel exhaust increases arterial stiffness in man. Part Fibre Toxicol. 2009; 6: 7.

37. Fang SC, Eisen EA, Cavallari JM, Mittleman MA, Christiani DC. Acute changes in vascular function among welders exposed to metal-rich particulate matter. Epidemiology. 2008; 19: 217-225.

38. O'Neill MS, Diez-Roux AV, Auchincloss AH, Shen M, Lima JA, Polak JF, Barr RG, Kaufman J, Jacobs DR, Jr. Long-term exposure to airborne particles and arterial stiffness: the Multi-Ethnic Study of Atherosclerosis (MESA). Environ Health Perspect. 2011; 119: 844-851.

39. Lenters V, Uiterwaal CS, Beelen R, Bots ML, Fischer P, Brunekreef B, Hoek G. Longterm exposure to air pollution and vascular damage in young adults. Epidemiology. 2010; 21: 512-520.

40. Suh HH, Zanobetti A. Exposure error masks the relationship between traffic-related air pollution and heart rate variability. J Occup Environ Med. 2010; 52: 685-692.

41. Grahame TJ. PM2.5 Species: Importance of Accurate Measurement. Epidemiology. $2014 ; 25: 615$.

42. Mustafic $\mathrm{H}$, Jabre $\mathrm{P}$, Caussin $\mathrm{C}$, Murad MH, Escolano S, Tafflet M, Perier MC, Marijon E, Vernerey D, Empana JP, Jouven X. Main air pollutants and myocardial infarction: a systematic review and meta-analysis. JAMA. 2012; 307: 713-721. 
43. Shah AS, Langrish JP, Nair H, McAllister DA, Hunter AL, Donaldson K, Newby DE, Mills NL. Global association of air pollution and heart failure: a systematic review and metaanalysis. Lancet. 2013; 382: 1039-1048.

44. Shah AS, Lee KK, McAllister DA, Hunter A, Nair H, Whiteley W, Langrish JP, Newby DE, Mills NL. Short term exposure to air pollution and stroke: systematic review and metaanalysis. BMJ. 2015; 350: h1295.

45. Brook RD, Shin HH, Bard RL, Burnett RT, Vette A, Croghan C, Thornburg J, Rodes C, Williams R. Exploration of the rapid effects of personal fine particulate matter exposure on arterial hemodynamics and vascular function during the same day. Environ Health Perspect. 2011; 119: 688-694.

46. Krishnan RM, Adar SD, Szpiro AA, Jorgensen NW, Van Hee VC, Barr RG, O'Neill MS, Herrington DM, Polak JF, Kaufman JD. Vascular responses to long- and short-term exposure to fine particulate matter: MESA Air (Multi-Ethnic Study of Atherosclerosis and Air Pollution). J Am Coll Cardiol. 2012; 60: 2158-2166.

47. He F, Shaffer ML, Li X, Rodriguez-Colon S, Wolbrette DL, Williams R, Cascio WE, Liao D. Individual-level PM(2).(5) exposure and the time course of impaired heart rate variability: the APACR Study. J Expo Sci Environ Epidemiol. 2011; 21: 65-73.

48. Patel RS, Al Mheid I, Morris AA, Ahmed Y, Kavtaradze N, Ali S, Dabhadkar K, Brigham K, Hooper WC, Alexander RW, Jones DP, Quyyumi AA. Oxidative stress is associated with impaired arterial elasticity. Atherosclerosis. 2011; 218: 90-95.

49. Vlachopoulos C, Dima I, Aznaouridis K, Vasiliadou C, loakeimidis N, Aggeli C, Toutouza M, Stefanadis C. Acute systemic inflammation increases arterial stiffness and decreases wave reflections in healthy individuals. Circulation. 2005; 112: 2193-2200. 
50. Lin W, Huang W, Zhu T, Hu M, Brunekreef B, Zhang Y, Liu X, Cheng H, Gehring U, Li C, Tang X. Acute respiratory inflammation in children and black carbon in ambient air before and during the 2008 Beijing Olympics. Environ Health Perspect. 2011; 119: 1507-1512.

51. Fang SC, Mehta AJ, Alexeeff SE, Gryparis A, Coull B, Vokonas P, Christiani DC, Schwartz J. Residential black carbon exposure and circulating markers of systemic inflammation in elderly males: the normative aging study. Environ Health Perspect. 2012; 120: 674680.

52. Langrish JP, Unosson J, Bosson J, Barath S, Muala A, Blackwell S, Soderberg S, Pourazar J, Megson IL, Treweeke A, Sandstrom T, Newby DE, Blomberg A, Mills NL. Altered nitric oxide bioavailability contributes to diesel exhaust inhalation-induced cardiovascular dysfunction in man. J Am Heart Assoc. 2013; 2: e004309.

53. Langrish JP, Lundback M, Mills NL, Johnston NR, Webb DJ, Sandstrom T, Blomberg A, Newby DE. Contribution of endothelin 1 to the vascular effects of diesel exhaust inhalation in humans. Hypertension. 2009; 54: 910-915.

54. Peretz A, Sullivan JH, Leotta DF, Trenga CA, Sands FN, Allen J, Carlsten C, Wilkinson CW, Gill EA, Kaufman JD. Diesel exhaust inhalation elicits acute vasoconstriction in vivo. Environ Health Perspect. 2008; 116: 937-942.

55. Mahmud A, Feely J. Effect of smoking on arterial stiffness and pulse pressure amplification. Hypertension. 2003; 41: 183-187.

56. Mahmud A, Feely J. Effects of passive smoking on blood pressure and aortic pressure waveform in healthy young adults--influence of gender. Br J Clin Pharmacol. 2004; 57: 37-43. 
57. Lucking AJ, Lundback M, Barath SL, Mills NL, Sidhu MK, Langrish JP, Boon NA, Pourazar J, Badimon JJ, Gerlofs-Nijland ME, Cassee FR, Boman C, Donaldson K, Sandstrom T, Newby DE, Blomberg A. Particle traps prevent adverse vascular and prothrombotic effects of diesel engine exhaust inhalation in men. Circulation. 2011; 123: 1721-1728. 